\title{
Transatlantica
}

Revue d'études américaines. American Studies Journal

\section{Paul Carmignani. Shelby Foote. Un sudiste au carré.}

Paris : Belin, 1998. 128 p.

Michel Bandry

\section{CpenEdition}

Journals

Édition électronique

URL : http://journals.openedition.org/transatlantica/717

DOI : $10.4000 /$ transatlantica. 717

ISSN : $1765-2766$

Éditeur

AFEA

Référence électronique

Michel Bandry, «Paul Carmignani. Shelby Foote. Un sudiste au carré. », Transatlantica [En ligne], 1 | 2003, mis en ligne le 05 avril 2006, consulté le 29 avril 2021. URL : http://journals.openedition.org/

transatlantica/717 ; DOI : https://doi.org/10.4000/transatlantica.717

Ce document a été généré automatiquement le 29 avril 2021

\section{(c) (i) $\odot$}

Transatlantica - Revue d'études américaines est mis à disposition selon les termes de la licence Creative Commons Attribution - Pas d'Utilisation Commerciale - Pas de Modification 4.0 International. 


\section{Paul Carmignani. Shelby Foote. Un sudiste au carré.}

Paris : Belin, 1998. 128 p.

Michel Bandry

1 L'excellent petit volume de la collection Voix américaines que consacre Paul Carmignani à Shelby Foote est un hommage raisonné au « doyen des lettres sudistes ». Hommage naturel de la part de quelqu'un qui a par ailleurs longuement écrit sur Foote. Hommage raisonné car l'admiration que voue Carmignani à Foote est fondée sur une longue pratique et une connaissance remarquable de l'oeuvre ainsi que sur une appréciation lucide de sa place dans la littérature sudiste.

2 Surtout connu dans son pays pour sa magistrale histoire de la guerre de Sécession en trois volumes et la série télévisée qui en a été tirée, Shelby Foote est historien et romancier. Il est vrai que l'histoire de la guerre est sous-titrée « récit », Foote disant lui-même que histoire et roman « ont tous deux pour objectif...de recréer le passé par leur méthode respective et de le faire revivre dans le monde qui les entoure ». L'une et l'autre permettent de "dire tout le Sud", selon l'ambition avouée d'un écrivain qui consacra vingt ans de sa vie à écrire la chronique de l'événement charnière de l'histoire du Sud et retraça une partie de l'histoire du Delta en quatre romans et un recueil de nouvelles. Dire le Sud, cela semble être le projet de tout écrivain sudiste véritable et l'on appréciera les quelques pages denses où Carmignani livre le fruit d'une réflexion longuement mûrie sur le Sud comme topos littéraire, la spécificité de la littérature du Sud, le poids de l'histoire, pour situer son auteur et, en fait, montrer son originalité profonde. Si Foote, à l'instar de Faulkner, a « son » comté, ce n'est pas pour « créer un cosmos qui soit à lui » mais pour en dire l'histoire, tenter de trouver la vérité et comprendre son pays. Refuser l'image trompeuse de la société harmonieuse d'un Sud idéalisé, éviter la tentation d'une représentation mimétique faisant place au pittoresque et à une certaine forme d'humanité, mais dire la crise, les moments oubliés qui ont fait l'histoire, dire la faute, le destin de l'homme du Sud, fruit de sa terre, de son temps et du passé. 
Les romans du cycle de Jordan County, publiés entre 1949 et 1954, Tournament, Follow Me Down, Love in a Dry Season, Shiloh et Jordan County, mettent en scène des moments de l'histoire du Delta et du Sud liés aux moments clé de l'épopée humaine. La lecture qu'en donne Carmignani met en évidence la cohérence de l'ensemble, cohérence qui apparaît également avec September September (1977), sorte de coda qui intègre la turbulence de la fin des années cinquante. Foote n'est pas un témoin de son temps comme on le dit de ces romanciers ou autres chroniqueurs d'une époque, il est une voix exigeante et forte qui met à jour la réalité du Sud à travers son histoire. Ce petit livre rappelle utilement l'importance d'un des grands écrivains sudistes. Qu'il donne envie de le lire!

INDEX

Thèmes : Recensions

\section{AUTEUR}

MICHEL BANDRY

Université Paul-Valéry - Montpellier 3 